doi: 10.17492/mudra.v2i2.9665

\title{
New Development Bank: Importance and Role in Sustainable Economic Development
}

\author{
K.B Dhore*
}

\begin{abstract}
As of 2014, the five BRICS countries represent almost 3 billion people which is $40 \%$ of the world population, with a combined nominal GDP of US\$16.039 trillion (20\% world GDP) and an estimated US\$4 trillion in combined foreign reserves. As of 2014, the BRICS nations represented 18 percent of the world economy. BRICS leaders have approved creating a New Development Bank which would fund long-term investment in infrastructure and more sustainable development. It then estimates the likely level of loans that this New Development Bank could make, under different assumptions. It highlights the complementary role that such a bank would play with existing development banks and shows its importance for enhancing the influence of BRICS and other developing countries in the international development architecture. On the other hand, there are doubts about the nature and coherence of the group. There is also concern that the economic agenda of BRICS could pose new challenges to human rights and development, particularly given the absence of domestic frameworks for accountability on international engagements.
\end{abstract}

Keywords: Sustainable Development, World Population, GDP, Infrastructure.

\subsection{Introduction}

BRICS, the acronym for an association of five major emerging national economies: Brazil, Russia, India, China, and South Africa, was originally known as "BRIC" before the inclusion of South Africa in 2010. The first formal summit in South Africa began efforts to join the BRIC grouping, and the process for its formal admission began in August of that year. South Africa officially became a member nation on 24 December 2010, after being formally invited by the BRIC countries to join the group. The group was renamed BRICS - with the "S" standing for South Africa - to reflect the group's expanded membership.

*Department of Economics, SNDT Women's University, Mumbai. 
There has been a fundamental change in the international economy, especially so in the last decade. Emerging and developing countries have significantly increased their weight in global GDP and especially in global economic growth. In particular, they have been responsible for most of the growth in the world economy since the 2007-2008 crisis. Perhaps most important in the context of this paper, some emerging and developing economies have accumulated very large long-term foreign exchange assets, which they have been typically placed in Sovereign Wealth Funds. The share in the world total, as well as the absolute level of foreign exchange reserves that emerging and developing countries have accumulated, has also grown remarkably in the last decade. A large part of these resources are invested in developed countries, with relatively low yields (see, for example, Griffith-Jones, 2011). At the same time, there are very large unmet needs in the emerging and developing countries, most clearly in the field of infrastructure and more environmentally sustainable forms of development where a deficit of investment of up to around US\$1 trillion annually has been identified beyond what is currently likely to be financed (Bhattacharya, Romani and Stern, 2012; Bhattacharya and Romani, 2013). The persistence of such a major deficit would constrain future growth of developing and emerging economies, as well as imply that a large proportion of the world's population would continue to have access to electricity and clean water. The fact that emerging and developing countries have the necessary savings and foreign exchange reserves to finance a New Development Bank that could contribute to finance such investment makes a clear case for such an institution to be created.

In this context, it is very welcome that the leaders of the BRICS countries (i.e. Brazil, the Russian Federation, India, China, and South Africa) approved in March 2013, during their meeting in Durban, the creation of a New Development Bank (NDB) to finance investment in infrastructure and more sustainable development in BRICS and other emerging and developing countries. This is reflected in the March 2013 Durban Summit Declaration and Action Plan: "In March 2012 we directed our Finance Ministers to examine the feasibility and viability of setting up a New Development Bank for mobilizing resources for infrastructure and sustainable development projects in BRICS and other emerging economies and developing countries, to supplement the existing efforts of multilateral and regional financial institutions for global growth and development... We have agreed to establish the New Development Bank. The initial contribution to the Bank should be substantial and sufficient for the Bank to be effective in financing infrastructure" (BRICS, 2013: paragraph 9).

The rest of the paper is structured as follows: section 2 outlines the importance of the New Development Bank and places it in the context of the broader needs of a 
South-South financial architecture. Section 4 addresses features that the New Development Bank would need to achieve its envisaged mandate, including possible trade-offs, where these exist. Naturally, the ultimate decisions on the size and other features of the New Development Bank will be taken by the BRICS governments themselves, but discussions of the technical options, and of related relevant experiences, may provide helpful inputs for those decisions. The type of issues to be discussed will include the capital level, as well as its structure, the scope of its lending, as well as its governance structure. Section 4 discusses the role of NDB in context of climate change and Section 5 concludes.

\subsection{Importance of New Development Bank (NDB)}

The New Development Bank, formerly referred to as the BRICS Development Bank, is a multilateral development bank operated by the BRICS states (Brazil, Russia, India, China and South Africa) as an alternative to the existing US-dominated World Bank and International Monetary Fund. This is just the beginning of a new international economic order; it will be a gradual, but steady process. The establishment of the NDB has longterm implications for global order and development. Not everybody would agree on the importance of the NDB, but the creation of the NDB is significant for future international order for three reasons.

First, it demonstrates the viability and dynamics of the BRICS despite all the scepticism and criticism in recent years. Some of the criticisms are legitimate as BRICS nations have experienced slower growth lately; even China's economic growth appears to be slowing down due to a variety of reasons. Critics of the NDB also point to different views among the members as evidence of serious problems of the bank. But this misses the point. There always will be different opinions and views among the BRICS countries, just like there are differences among G7 members. What is important, however, is whether member states share a major common goal that can unite them despite differences. The answer is: development. Unlike G7 member states, BRICS members are largely still developing countries and this situation means that for a long time these countries will focus on how to improve the living standards of their citizens. Also, other developing countries are desperate in need of funding for infrastructure projects.

Second, the NDB demonstrates China's global leadership. Given China's huge size and quick development, there is little doubt that the world truly needs China's leadership. What China needs to be careful about is to maintain a balance between its own influence on the bank and other members' impact. It is thus critical for China to 
avoid the impression that China dominates the NDB. Unlike the U.S., China should not try to impose its own will and rules on other members and developing countries seeking funding from the bank. This is especially the case when BRICS members do have diverging interests and even conflicting interests (such as territorial disputes between China and India) among themselves. China should not use the NDB as a platform to only advance its own national interests such as the Renminbi's internationalization; instead, China should promote equality with the bank as a common platform for all developing countries to realize their development dreams. Thus it is a good sign that although Shanghai has been chosen as the headquarters of the new bank, the first president will be Indian the first chairman of the board of governors will be Russian, the first chairman of the board of directors will be Brazilian, and the first regional centre of the bank will be in South Africa.

Third, the NDB is significant because it is a direct challenge to the global order led by the West. Many view the NDB as a response to the failed reforms at the IMF and World Bank and developing countries like China and India cannot increase their influence within those institutions. However, it should be kept in mind that the NDB is not currently challenging the international liberal economic order. China and India are perhaps the two greatest beneficiaries of an open liberal economic order; and thus the NDB should try to push the IMF and World Bank to be more open and transparent. Ultimately the competition between the NDB and the IMF and World Bank should be about efficiency rather than a struggle between liberal vs. alternative economic philosophies. In this sense, there is a strong complementary relationship between the NDB, the IMF and the World Bank. That said, the West, the IMF and the World Bank should not view the NDB as a threat to their domination of the global economic order;

To be sure, the NDB is unlikely to replace the IMF and World Bank in the near future as the latter will still remain powerful players in the global economic order. The most likely relationship between the two is a complementary relationship rather than a conflicting one. That said, in the long run the competition between the two will intensify and the final outcome will depend on the balance of power between the two blocs: the developing world and the developed world. What is for sure is that we are in for some interesting times.

The creation of the NDB to finance infrastructure and sustainable development projects in emerging economies is a landmark achievement. Developing nations have lost faith in the current system with its strict conditions on development finance and its inability to insulate countries from financial shocks. International observers have, however, expressed mixed views about the creation of the bank and what it represents for the nascent multilateral BRICS bloc of Brazil, Russia, India, China and South Africa. 
Some remarked that the NDB represents a timely response to the failure of the existing Bretton-Woods institutions to adequately represent the needs of emerging economies. Others, however, are sceptical of the NDB's capacity to address these issues, noting that existing rifts between BRICS nations could undermine the initiative. Despite these criticisms, the creation of the NDB is a positive step for the BRICS nations and developing countries in general. While it is not yet clear whether the NDB will pose a direct challenge to the global financial status quo, its creation presents a number of opportunities for the developing nations.

First, the creation of the NDB will strengthen .the voice of developing economies in shaping the future direction of global development finance. The BrettonWoods institutions, such as the World Bank and IMF, have long dominated the development agenda. These institutions have crafted development strategies and presented them as the only viable model for generating economic growth. It may be desirable for the BRICS to create the bank on their own as negotiations may be less complex and therefore quicker. However, there could be an option for broadening the membership left open for the future, and provisions could be easily made for such broadening when the BRICS bank would be created.

NDB would lend to both the BRICS countries themselves and to other developing countries. Furthermore, it would be desirable for it to have a balanced portfolio of loans that includes middle- and low-income countries from different regions, as this would make the bank more creditworthy, both because middle-income countries may be more creditworthy than low-income ones, and because it would ensure the benefits of geographical diversification. NDB would provide a valuable addition to the existing network of multilateral, regional and national development banks. Multilateral and regional development banks seem to perform far better their functions, including support for productive development through infrastructure investment, if they work closely with national development banks, which have far greater local knowledge. There are important similarities with other development banks in their initial phases, such as the World Bank, which also started life focusing on infrastructure. There is a strong case for a major step increase in investment in infrastructure and more sustainable development, based on the need for growth, structural change, inclusion as well as sustainability and resilience greater local knowledge.

\subsection{Features of the NDB}

This section will address features that the NDB could need to achieve its envisaged mandate, including possible trade-offs, where these exist. Naturally, the 
ultimate decisions on the NDB will be made by the BRICS Governments themselves, but discussions of the technical options, and of related relevant experiences (for example of the Development Bank of Latin America (CAF) and the EIB) may provide helpful insights for those decisions. We will discuss here the scope of NDB lending activities, the level and structure of its capital endowment, and its governance structure. How the NDB would cooperate with other development finance institutions, both public and private, will also be examined.

\subsection{Scope of lending and other instruments}

The scope of sectorial and country-specific lending of NDB has been clearly defined by the BRICS leaders in the Durban 2013 Summit Declaration as "mobilizing resources for infrastructure and sustainable development projects in BRICS and other emerging economies and developing countries". The fact that the unmet needs in the area of infrastructure and sustainable development are extremely large and that such investment is crucial for inclusive and more sustainable growth - with only half of it currently being met by existing financial sources - justifies the BRICS leaders' decision to focus the operations of NDB on this area. It is important for the move towards a greener economy that investment in infrastructure is broadly defined, so it also includes infrastructure investment such as for renewable energy, like solar, wind and others. A case could also be made for NDB to finance innovation regarding both the adaptation of technologies already developed to the conditions of emerging and developing economies and, even more ambitiously, the development of such innovation in the borrowing countries themselves. In this regard, the EIB's experience in allocating an increasingly large share of its financing to innovation could provide useful lessons.

Furthermore, given that there are unmet needs in other sectors in developing and emerging economies (like lending to SMEs, which is crucial for growth and employment, as well as financing innovation and innovative firms which is key for increasing productivity) and the risk-reducing effects of having a diversified portfolio, this may in future justify that the BRICS bank expands its scope into other sectors, like lending via commercial or development banks to SMEs. As regards the infrastructure and sustainable development sector, the overall un-met needs are massive.

This means that the scale of lending of the NDB needs to be large enough to make a meaningful impact. Below we discuss estimates for how much lending can be generated by a particular level of capital of NDB. Furthermore, the impact of NDB must be measured in terms of its capacity to leverage, through its co-financing of projects with the private and public sectors. National and regional development banks - as well as the 
World Bank - will be natural partners. It is interesting to note that regional or multilateral development banks are often most successful in those countries that have efficient and well-established national development banks. This is because of the valuable synergies between them with, for example, national development banks having greater local knowledge of national projects and local regulations as well as risks, and international or regional institutions having greater comparative experience of best international or regional practice, regarding engineering, design and financial packaging. An example was given in interviews with EIB senior management, who argued that outside Europe, the EIB found it particularly productive to work with countries like Turkey, because Turkey has a well-functioning national development bank.

An important issue is the quality of the loans made. There is a potential trade-off here between the speed of growth of a portfolio of loans and the quality of loans. Though the scale of operations is clearly important, a high quality of loans is an important priority as it maximizes the likely development impact of the projects and minimizes the risk of default on loans; the latter is important for improving the credit rating of the NDB. It is also important for ensuring that NDB makes profits on its loans, as those profits can be reinvested in the NDB, allowing an expansion of capital, which will facilitate increased lending in the future and Initial speed in building up a portfolio of loans should not be at the expense of the quality of projects. Devoting resources to project preparation, including with financial resources provided by NDB, is a key component for improving the quality of projects. Rigorous evaluation of projects by the $\mathrm{NDB}$, as well as a strong professional approach to such evaluations, is extremely important. Autonomy of management of NDB for approving only technically welldesigned projects is important. Indeed, the EIB and CAF pride themselves that their decision-making process is reportedly autonomous in that sense.

The more complex the products, the longer they take to be designed and implemented. So-called "plain vanilla" loans can be made much faster than more complicated loan structures. Transactions involving equity take even longer (though they have desirable features, such as capturing part of the "upside" if projects are very profitable). Therefore beginning with simple products can help quickly build up a portfolio of assets

The experience of the North Atlantic crisis (as the so-called global financial crisis can more precisely be labeled) that started in 2007-2008 indicates that complexity often breeds opaqueness and leads to greater risk and future losses, linked to the financial engineering and hidden excessive leverage. Indeed, though a BRICS bank may wish to assume greater project risks (e.g. investing in projects with less tested 
technologies, or investing in very poor countries, with weak existing infrastructure) when these projects have potential large developmental or other benefits, it should avoid taking purely financial risks that could lead to substantial losses. We refer to purely financial losses, in the sense of those instruments, like those that have higher embedded leverage, that can create higher returns, but also potentially very high losses. Public development banks should not be in the business of taking on such excessive financial risk, which has had such disastrous effects on private banks. For the above reasons, simplicity of instruments seems desirable, especially in the initial phases of NDB. Simplicity and transparency should also characterize the investments that NDB makes with any surplus liquid funds.

\subsection{Capital level}

As reported in the press, officials from Brazil, the Russian Federation, India, China and South Africa have agreed to set up the BRICS bank with a total capital of US\$50 billion, shared equally among them (Wall Street Journal, 28 August 2013). It has also been reported that 20 per cent of this capital, or US\$10 billion, would be paid-in. One proviso which should be mentioned here is that, once the BRICS bank is established, BRICS countries could consider making additional contributions to already paid-in capital, i.e. beyond the initial US $\$ 10$ billion this would have the advantage of generating future lending capacity in addition to that estimated below. One option that has been discussed in this context is that non-BRICS countries (emerging and developing, as well as developed ones) could also contribute capital - either right at the beginning or only after the bank has been established. Assuming a total capital endowment of US $\$ 100$ billion, of which 20 per cent would have been paid in, the level of annual lending could reach, after 20 years, a stock of loans of up to US\$350 billion, equivalent to about US $\$ 34$ billion annually. The latter amount could be used for investment projects worth at least US\$68 billion annually, given that there would be co-financing by private and public lenders and investors. In what follows, we outline in detail levels of lending of NDB under different scenarios and assumptions.

To estimate the level of loans that such a capital endowment would generate, it is useful to look at similar development banks. One valuable precedent is provided by the CAF, though the credit rating of BRICS countries, especially China, is somewhat higher than that of CAF member countries. Nevertheless, the CAF has the advantage of being an institution with a long and positive track record, including the fact that none of its borrowers has ever defaulted on any of its loans. In the period between 2007 and 2012, the average ratio of the total portfolio of CAF loans divided by its total available capital 
was 2.4. Here total available capital is defined as paid-in capital plus reserves and retained profits plus surplus capital. In the case of NDB, we can assume that in the first year there would be no retained profits, but these could start building up. Assuming paidin capital to amount to US\$10 billion, which is 20 per cent of the US\$50 billion of total capital in principle agreed by BRICS leaders, and applying the same leverage ratio as that of the CAF, the initial stock of loans that could be achieved would be US $\$ 24$ billion. Further assuming the average loan maturity to be ten years, the average annual loan level could be US $\$ 2.4$ billion. In this context we are assuming that lending would be based only on actually available capital, i.e. paid-in capital, given the priority to achieve a high rating

However, if we assume that the BRICS bank could make a return on its lending of, for example, five per cent, the accumulated profits could reach US $\$ 0.12$ billion the first year; if the profits were immediately retained and thus added to available capital, lending the next year could be five per cent higher. Therefore, profits in the second year would also be five per cent higher, which would further increase capital. By the power of compound interest, after a period of ten years, the total stock of accumulated lending would reach US $\$ 34$ billion, and total available capital would reach US\$14 billion. Therefore, annual lending could reach US $\$ 3.4$ billion. After a period of 20 years, the total stock of lending could reach US\$86 billion and total available capital would have increased to US $\$ 36$ billion.

\subsection{Geographical coverage of lending}

It seems clear that NDB would lend to both BRICS countries themselves and to other developing countries. Furthermore, it would seem desirable for the BRICS bank to have a balanced portfolio of loans that includes both middle-income and low-income countries from different regions, as this would be seen to make the bank more creditworthy, both because middle-income countries may be - or perceived to be - more creditworthy than low-income ones, and because it would ensure the benefits of geographical diversification that lowers risk, as problems in countries across regions are less correlated.

Clearly, however, sub-Saharan African countries have particularly large unmet infrastructure needs, and therefore there seems to be a case for greater priority to be given to lending to projects in that region. For lending to low-income countries, there could be a case for providing some subsidy element to make the loans concessional. One possibility for funding such a subsidy in the case of loans linked to more sustainable development would be to use international funds allocated for this purpose to finance the subsidy part of the loans, with the BRICS bank providing the loan itself. The rest could 
be financed by trust funds, funded by developed countries, in the context of existing international agreements.

\subsection{Links with other multilateral, regional and national development banks}

It seems important to think in terms of a system where synergies and complementarities exist between international, regional and national development banks. NDB would provide a valuable addition to that network of banks. It is evident that multilateral and regional development banks seem to perform far better their functions, including support for productive development through infrastructure investment, if they work closely with national development banks, which have far greater local knowledge. Moreover, such close collaboration also reduces asymmetries of information at the national level. Similarly, national development banks can operate better, if they have the financial and technical support of multilateral banks, such as the NDB. There has been a lot of emphasis on public-private financial partnerships, but equally or even more important are the links between multilateral, regional and national development banks. An important advantage of the NDB will be that this modus operandi - of close collaboration with national development banks - can be established right at its inception. Of course close collaboration with existing regional development banks and with the World Bank would also be an important feature of the NDB.

It is interesting that the mere proposal of NDB has reportedly encouraged a new proposal by the World Bank Group to launch a separate large Fund for Infrastructure financing in sub-Saharan Africa, which would have a separate governance structure than that of the World Bank, with greater participation for developing and emerging economies, and would provide additional funding for much needed infrastructure. The fact that the NDB, even before formally created, is already catalyzing an expansion and improvement of World Bank initiatives is to be welcomed. It illustrates how the creation of NDB will generate, both through competition as well as complementarities, valuable externalities in the rest of the development finance institutions, as well as of course by making a major direct significant contribution through its own lending. Broadly, the development of large and effective BRICS institutions, like the Contingent Reserve Arrangement and the NDB, can be a valuable platform for the BRICS advancing reforms in the international financial and development architecture that favour developing and emerging countries in general. Scale of the new institutions, as well as speed in establishing them, and making them effective, will significantly enhance such potential bargaining power for encouraging meaningful reform. 


\subsection{BRICS and Climate Change}

The Environment Ministers of Brazil, Russia, India, China and South Africa (BRICS) gathered for their first official meeting on 22 April, 2015 to discuss green economy development and cooperation in tackling climate change. The Ministers highlighted that sustainable development should address in particular: poverty eradication; changing unsustainable and promoting sustainable patterns of consumption and production (SCP); protecting and managing the natural resource base of economic and social development; and addressing climate change.

During the said meeting, in Moscow, the BRICS Environment Ministers decided to: establish a Working Group on environment to identify and discuss priority areas of cooperation, which will convene its first meeting in 2015 in Russia; explore the potential of the BRICS New Development Bank for funding environmental projects; explore the possibility of establishing a collaborative platform of the BRICS countries, intended to share best environmental practices and facilitate the exchange of environmentally sound technologies and know-how with participation of public and private stakeholders; and hold regular meetings of Environment Ministers of BRICS.

They further said that they will consolidate efforts in their countries to develop policies contributing to mitigation efforts and adaptation of the national economies to the impacts of climate change, in accordance with the principles of: equity; common but differentiated responsibilities (CBDR) and respective capabilities (RC); and other provisions of the UN Framework Convention on Climate Change (UNFCCC). "The BRICS nations hold a unique position as leading emerging economies and political powers at the regional and international level. Whilst mature economies across the globe grapple with towering budget deficits, anemic growth and rising unemployment, the BRICS are expanding rapidly, lifting people out of poverty and driving the global economy," Achim Steiner, UN Environmental Programme (UNEP) Executive Director, told the meeting.

Steiner further noted that the BRICS' efforts towards establishing an environmental public-private partnership (PPP) mechanism to facilitate investment in green technologies and related environmental projects in BRICS countries provide an opportunity to expedite and strengthen the global transition to a green economy. Innovative financial mechanisms under the BRICS, such as the New Development Bank and the Contingent Reserve Arrangement, have the potential to construct an enduring green infrastructure, longer-term competitiveness for the BRICS economies and strengthen South-South cooperation, he added. 


\subsection{Conclusion}

Emerging and developing countries have significantly increased their weight in global GDP and in global economic growth. Perhaps most importantly, some emerging and developing economies have accumulated very large long-term foreign exchange assets, which they have typically placed in Sovereign Wealth Funds. A large part of these resources are invested in developed countries, with relatively low yields. At the same time, there are very large unmet needs in the emerging and developing countries in the field of infrastructure and more environmentally sustainable forms of development. A shortfall of investment of approximately US $\$ 1$ trillion annually has been identified by Bhattacharya, Romani and Stern (2012), beyond what is likely to be financed with current institutions. Emerging and developing countries have the necessary savings and foreign exchange reserves to finance a new development bank that could contribute to finance such investment. The fact that the leaders of the BRICS nations have committed to the creation of a new Development Bank for infrastructure and sustainable development is very welcome. This institution would be a complement, not a substitute, for existing financial institutions both in the public and the private sector. Its existence would also strengthen the voice of developing and emerging economies in the development finance architecture. It is encouraging that BRICS leaders have also proposed the creation of other institutions, such as the Contingency Reserve Arrangements (CRA), amongst BRICS countries, which would provide official liquidity in times of need. There are important similarities with other development banks in their initial phases, such as the World Bank, which also started life focusing on infrastructure. There is a strong case for a major step increase in investment in infrastructure and more sustainable development, based on the need for growth, structural change, inclusion as well as sustainability and resilience.

The scale of lending of the NDB needs to be large enough to make a meaningful impact given the very large scale of needs identified. Furthermore, the impact of a NDB must be measured in terms of its capacity to leverage, through its co-financing of projects with the private and public sectors. National and regional development banks, as well as the World Bank, will be natural partners. An important issue is the quality of the loans made. There is a potential trade-off between the pace of growth of a portfolio of loans and the quality of loans. Though scale of operations is clearly important, a high quality of loans is a priority as it maximizes the likely development impact of the projects and minimizes risk of default; the latter is key for improving the credit rating of NDB. It is also important that NDB make profits on its loans, as those can be reinvested, allowing an expansion of capital, which will facilitate increased lending. 


\section{Weblinks}

www.financialexpress.com/news/brics-summit-india-likely-to-get-presidency-of-bricsbank-china-to-bag-hq/1270149

unctad.org/en/PublicationsLibrary/osgdp20141_en.pdf

allafrica.com/stories/201407231215.html?page $=2$

www.caei.com.ar/sites/default/files/19_3.pdf

www.imf.org/external/np/sec/memdir/members.aspx

www.washingtonpost.com/blogs/monkey-cage/wp/2014/07/17/what-the-new-bank

f-brics-is-all-about/

www.eastasiaforum.org/2011/05/22/brics-and-the-international-economic-order-ani dea-whose-time-has-come/

www.eastasiaforum.org/2014/07/31/brics-lay-a-foundation-but-will-there beconcrete-action/

articles.economictimes.indiatimes.com/2014-017/news/51657028_1_infrastructurefunding-world-bank-brics-countries

www.cccep.ac.uk/publications/policy/docs/pp-infrastructure-for-development-meetingthe-challenge.pdf

www.economist.com/node/11488749

pib.nic.in/newsite/PrintRelease.aspx?relid=106712

climate-l.iisd.org/news/brics-environment-ministers-discuss-green-economy-climatechange/. 